\title{
Azithromycin induces anti-viral responses in bronchial epithelial cells
}

\author{
V. Gielen*,\#,ף, S.L. Johnston*,\#,ף and M.R. Edwards*,\#,ף
}

ABSTRACT: The majority of asthma exacerbations are caused by rhinovirus. Currently the treatment of asthma exacerbations is inadequate. Previous evidence suggests that macrolide antibiotics have anti-inflammatory and antiviral effects; however, the mechanism is unknown.

We investigated the anti-rhinoviral potential of macrolides through the induction of antiviral gene mRNA and protein. Primary human bronchial epithelial cells were pre-treated with the macrolides azithromycin, erythromycin and telithromycin, and infected with minor-group rhinovirus 1B and major-group rhinovirus 16. The mRNA expression of the antiviral genes, type $I$ interferon- $\beta$ and type III interferon- $\lambda 1$, interferon- $\lambda 2 / 3$, and interferon-stimulated genes (retinoic acid inducible gene I, melanoma differentiation associated gene 5 , oligoadenylate synthase, MxA and viperin) and pro-inflammatory cytokines (interleukin (IL)-6 and IL-8), and rhinovirus replication and release were measured.

Azithromycin, but not erythromycin or telithromycin, significantly increased rhinovirus 1B- and rhinovirus 16-induced interferons and interferon-stimulated gene mRNA expression and protein production. Furthermore, azithromycin significantly reduced rhinovirus replication and release. Rhinovirus induced IL- 6 and IL-8 protein and mRNA expression were not significantly reduced by azithromycin pre-treatment.

In conclusion, the results demonstrate that azithromycin has anti-rhinoviral activity in bronchial epithelial cells and, during rhinovirus infection, increases the production of interferon-stimulated genes.

KEYWORDS: Cytokines, inflammation, lung, viral

$\mathbf{R}$ espiratory viral infections are associated with the majority of asthma exacerbations $(\sim 80 \%)$ in both adults $[1,2]$ and children $[3,4]$. Asthma exacerbations are the major cause of morbidity, mortality and healthcare costs in asthma [5]. The mechanisms of virus-induced asthma exacerbations are poorly understood [6]. Inhaled corticosteroids reduce asthma exacerbation frequency [7-9]; however, this effect is only partial even in combination with long-acting $\beta_{2-}$ agonists [10, 11], more effective therapies are therefore necessary. Rhinoviruses (RV) are responsible for $\sim 60 \%$ of virus-induced exacerbations [1, 4]. Asthmatics have an increased susceptibility to RV infection compared with normal subjects [1]. A novel mechanism for this increased susceptibility has been identified recently: asthmatics exhibit lower levels of interferon (IFN)- $\beta$ and IFN- $\lambda$ gene and protein expression upon RV infection $[12,13]$ and IFN- $\lambda$ levels negatively correlate with exacerbation severity [13].

Type I IFNs consist of the single gene IFN- $\beta$ and numerous IFN- $\alpha$. The recently discovered type III IFNs consist of IFN- $\lambda 1,2$ and 3 (respectively IL-29,
IL-28A and IL-28B). The major IFNs produced by bronchial epithelial cells are IFN- $\beta$ and $-\lambda$ [14]. Despite using different receptor complexes, both types of IFNs have functional similarities, including antiviral effects through stimulation of the innate and adaptive immune responses. After secretion, IFNs bind to the surface of infected and neighbouring cells to initiate the Janusactivated kinases (JAKs) and the signal transducers and activators of transcription (STATs). Activation of the JAK-STAT pathway leads to the induction of many IFN-stimulated genes (ISGs), which prevent viral replication, such as MxA [15], viperin [16] or the $2^{\prime}-5$ ' oligoadenylate synthetase (OAS) family [17], and also recognise viral RNA, such as retinoic acid inducible gene (RIG)-I [18], and melanoma differentiation associated gene (MDA) 5 [19]. As asthmatics have defective IFN- $\beta$ and IFN- $\lambda$ expression, one potential approach to therapy of asthma exacerbations is to augment host IFN responses and induction of antiviral ISG expression.

Macrolides include erythromycin (EM), azithromycin (AM) and the ketomacrolide telithromycin (Tel). They have well-established antibacterial
AFFILIATIONS

${ }^{*}$ MRC and Asthma UK Centre for Allergic Mechanisms of Asthma, ${ }^{*}$ Centre for Respiratory Infections and Dept of Respiratory Medicine, and

"National Heart and Lung Institute \& Wright-Fleming Institute for Infection and Immunity, Imperial College London, London, UK.

\section{CORRESPONDENCE}

M.R. Edwards

Dept of Respiratory Medicine

National Heart \& Lung Institute

St Mary's Campus

Imperial College London

W2 1PG

London

UK

E-mail: michael.edwards@ic.ac.uk

Received:

June 172009

Accepted after revision:

Feb 042010

First published online:

Feb 112010

Online ISSN 1399-3003 
[20] and anti-inflammatory effects [21-23], and preliminary evidence showed that they may also have antiviral effects [2427]. The antibacterial action of macrolides is through inhibition of protein synthesis via binding to the $50 \mathrm{~S}$ subunit of bacterial ribosomes. Macrolides also inhibit interleukin (IL)-6 and IL-8 protein production and reduce neutrophil attraction to the site of infection, likely through inhibiting nuclear factor (NF)- $\kappa B$ $[21,28]$. Tel was reported to have a beneficial effect in treatment of asthma exacerbations, with Tel-treated patients experiencing greater improvements in lower airway symptoms and lung function compared with placebo-treated patients though the mechanisms of this therapeutic effect are unknown [29]. In vitro studies report an anti-rhinoviral and antiinflammatory effect of some macrolide antibiotics [24, 26, 27], possibly via a reduction of intercellular adhesion molecule (ICAM)-1 mRNA expression after major-group RV infection, which use ICAM-1 as their receptor. In contrast, antiviral effects were also observed for minor group RVs, which utilise a different receptor $[26,27]$. The mechanisms for this effect are therefore unknown.

We hypothesised that the beneficial effects of macrolide antibiotics in asthma exacerbations may be due, at least in part, to their ability to exhibit antiviral activity. In the current study, we used in vitro models of normal primary human bronchial epithelial cell (HBEC) culture and investigated the effects of the macrolides AM, EM and Tel on IFN and ISG gene expression, ISG protein induction and also the antiviral activity during RV infection.

\section{MATERIALS AND METHODS}

\section{Cell and virus culture}

HBECs (Lonza, Cleveland, OH, USA) were cultured in bronchial epithelial cell growth medium according to manufacturer's recommendations. RV1B and RV16 (ATCC, Rockville, IN, USA) were prepared as previously described [30], and were titrated on HeLa cells to ascertain their $50 \%$ tissue culture infective dose (TCID50) per mL [31]. The identity of each virus was confirmed by inhibition with serotypespecific antibody using titration assays. Both viruses were negative for Mycoplasma infection.

\section{Treatment with macrolides and infection of HBECs with RV1B}

HBECs were cultured in 12-well tissue culture plates (Nunc, Rochester, NY, USA) until 80-90\% confluent before being treated with AM, EM (Sigma-Aldrich, St Louis, MA, USA), and Tel (a kind gift from Sanofi Aventis, Guildford, UK) at a concentration of $10 \mu \mathrm{M}$ or $50 \mu \mathrm{M}$ in bronchial epithelial basal medium (BEBM) for 24h. The diluent used for all three macrolides was $96 \%$ ethanol, at a final concentration of $0.05 \%$ for $50 \mu \mathrm{M}$ macrolides and was confirmed in preliminary experiments not to have any effect on measured outcomes (data not shown). HBECs were then infected with RV1B, at multiplicity of infection (MOI) 1 or 0.25 , or RV16 (MOI of 1 ) for $1 \mathrm{~h}$ with shaking at room temperature and replaced with $1 \mathrm{~mL}$ of BEBM. After 8, 24 and $48 \mathrm{~h}$, supernatants and cells were harvested in RLT-buffer (Qiagen, Crawley, UK) for RNA isolation, or in $2 \%$ Tris-glycine SDS sample buffer (Invitrogen, Paisley, UK) for protein. Supernatants and lysates were stored at $-80^{\circ} \mathrm{C}$ until analysis.

\section{RNA isolation and cDNA synthesis}

Total RNA isolation was performed using RNeasy ${ }^{\circledR}$ mini kit (Qiagen) according to the manufacturer's recommendations. cDNA was prepared using random primers (Promega, Maddison, WI, USA) and Omniscript RT kit (Qiagen) according to manufacturers' recommendations and stored at $-80^{\circ} \mathrm{C}$.

\section{TaqMan real-time PCR}

In a $25-\mu \mathrm{L}$ PCR reaction, $2 \mu \mathrm{L}$ cDNA was amplified in a 7500 Sequence Detector, using the $2 \times$ QuantiTect Probe PCR Master Mix (Qiagen), $50 \mathrm{nM}$ forward primer, $300 \mathrm{nM}$ reverse primer and $100 \mathrm{nM}$ probe were used for RV, $300 \mathrm{nM}$ primers and $100 \mathrm{nM}$ probe were used for the $18 \mathrm{~S}$ rRNA internal control, $300 \mathrm{nM}$ forward primer, $900 \mathrm{nM}$ reverse primer and $100 \mathrm{nM}$ probe for oligoadenylate synthetase (OAS), IL-29 and IFN- $\beta$, and $900 \mathrm{nM}$ primers and $100 \mathrm{nM}$ probes for myxovirus resistance A $(\mathrm{MxA})$, viperin, IL-28, IL-6, IL-8, retinoic acidinducible gene (RIG)-I and melanoma differentiation associated gene (MDA)5 (all FAM-TAMRA labelled). Sequences of primers and probes used are listed in table 1. The copy numbers were determined via standard curves of each gene constructed as dsDNA plasmids and normalised with the housekeeping gene $18 \mathrm{~S}$ rRNA. Data are presented as percentage of copy number of control wells (RV1B), from $\sim 2.5 \times 10^{5}$ cells $\cdot$ well $^{-1}$.

\section{ELISA}

IL-6 and IL- 8 were quantified by ELISA using commercially available paired antibodies and standards, following the manufacturer's instructions (R\&D Systems, Abingdon, UK). The sensitivity of each assay was $10 \mathrm{pg} \cdot \mathrm{mL}^{-1}$.

\section{SDS-PAGE and western blotting}

Total protein lysates were run on $4-12 \%$ Bis-Tris polyacrylamide gels, and transferred onto nitrocellulose membranes (Invitrogen), blocked in 5\% skimmed milk, and probed with antibodies specific for human RIG-I $0.083 \mu \mathrm{g} \cdot \mathrm{mL}^{-1}$ (Cell Signaling, Danvers, MA, USA), RSAD2/viperin $0.3 \mu \mathrm{g} \cdot \mathrm{mL}^{-1}$ (ProteinTech Group, Chicago, IL, USA), OAS1 $0.5 \mu \mathrm{g} \cdot \mathrm{mL}^{-1}$ (Abgent, San Diego, CA, USA), MxA $0.2 \mu \mathrm{g} \cdot \mathrm{mL}^{-1}$ (Santa Cruz Biotechnology, Inc., Santa Cruz, CA, USA) or $\alpha$-tubulin $0.2 \mu \mathrm{g} \cdot \mathrm{mL}^{-1}$ (Santa Cruz Biotechnology, Inc.). Secondary antibodies used were goat anti-mouse horseradish peroxidise (HRP) conjugate $0.08 \mu \mathrm{g} \cdot \mathrm{mL}^{-1}$ and sheep anti-rabbit HRP conjugate $2 \mu \mathrm{g} \cdot \mathrm{mL}^{-1}$ (AbD Serotec, Oxford, UK). Blots were developed using ECL (GE Healthcare, Chalfont St Giles, UK).

\section{Virus titration assay}

Supernatants were serially diluted in DMEM containing $4 \%$ fetal calf serum (Invitrogen) and titrated on HeLa cells to determine the TCID $50 \cdot \mathrm{mL}^{-1}$ of the RV in the supernatants. Each dilution was assayed in eight replicates, and TCID50 $\cdot \mathrm{mL}^{-1}$ was calculated according to the Spearman-Karber formula [31].

\section{Statistical analysis}

All data are presented as mean \pm SEM. Comparisons of different groups were analysed using ANOVA with Bonferroni posttesting (Prism, GraphPad Software, San Diego, CA, USA). A p-value $<0.05$ was considered significant. All experimental work was performed as 3-5 independent experiments. 


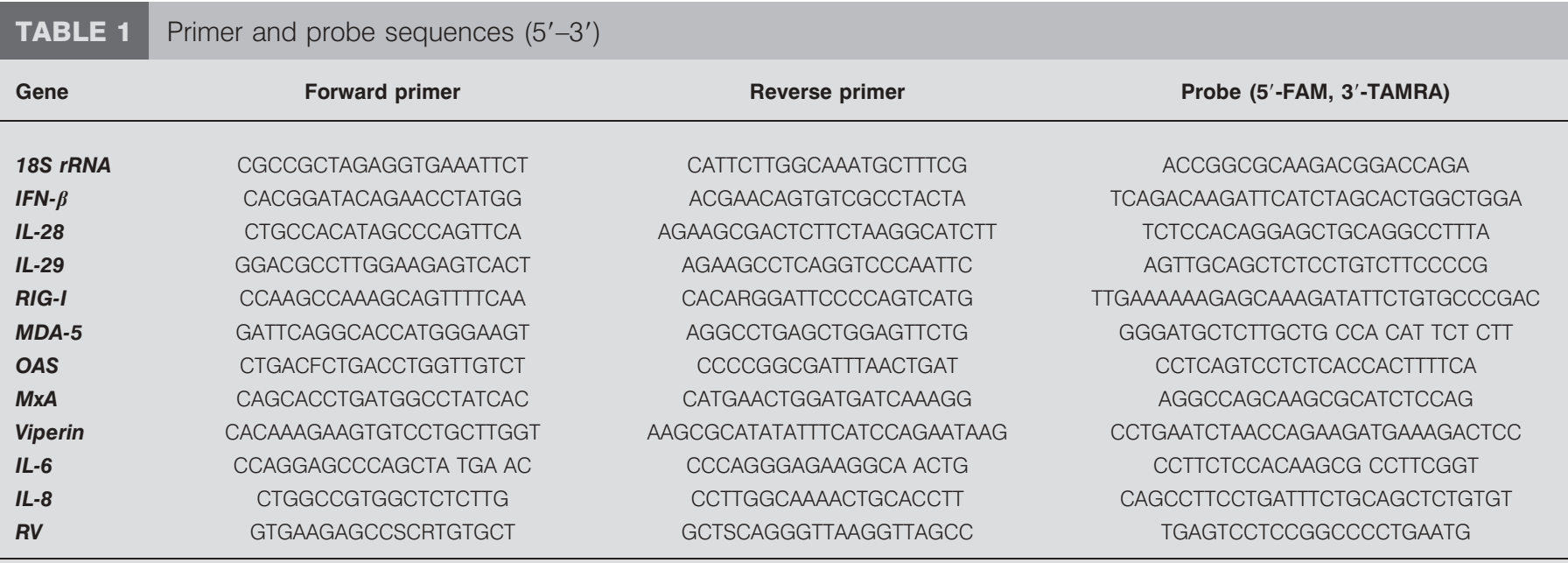

rRNA: ribosomal RNA; IFN: interferon gene; IL: interleukin gene; RIG-I: retinoic acid-inducible gene-l; MDA5: melanoma differentiation associated gene 5; OAS: oligoadenylate synthetase gene; $M \times A$ : myxovirus resistance A gene; RV: rhinovirus gene.

\section{RESULTS}

\section{RV1B increased type I and type III IFN and ISG mRNA expression}

At $8 \mathrm{~h}$ after infection, RV1B (MOI 0.25) significantly induced IL-28 mRNA expression ( $p<0.01$, data not shown) and at MOI 1 there was a significant induction of IL-28, MxA, RIG-I, MDA-5 $(\mathrm{p}<0.05)$ and OAS $(\mathrm{p}<0.01)$ compared with mediumtreated cells (data not shown). At $24 \mathrm{~h}$ after infection, RV1B significantly induced type I and type III IFNs and the ISGs measured at both RV1B concentrations compared with medium-treated cells. RV1B increased IFN- $\beta$ mRNA levels from $8.9 \times 10^{3}\left( \pm 4.4 \times 10^{3}\right)$ copy number per $2.5 \times 10^{5}$ cells to $1.6 \times 10^{5}\left( \pm 6.2 \times 10^{4}, \mathrm{p}<0.05\right)$ at MOI 0.25 and to $5.6 \times 10^{5}$ $\left( \pm 2.1 \times 10^{5}, \mathrm{p}<0.05\right)$ at MOI 1 ; IL-28 from $1.3 \times 10^{1}\left( \pm 1.1 \times 10^{1}\right)$ to $1.1 \times 10^{5}\left( \pm 4.3 \times 10^{4}, \mathrm{p}<0.05\right)$ at MOI 0.25 and to $5.6 \times 10^{5}$ $\left( \pm 3.0 \times 10^{5}, \mathrm{p}<0.05\right)$ at MOI 1 ; and IL-29 mRNA from $1.6 \times 10^{1}$ $\left( \pm 0.6 \times 10^{0}\right)$ to $3.2 \times 10^{3}\left( \pm 6.9 \times 10^{2}, \mathrm{p}<0.05\right)$ at MOI 0.25 and to $5.2 \times 10^{6}\left( \pm 3.3 \times 10^{4}, \mathrm{p}<0.05\right)$ at MOI $124 \mathrm{~h}$ post-infection. ISG mRNA levels were also significantly increased by RV1B $24 \mathrm{~h}$ post-infection; viperin was increased from $2.5 \times 10^{1}$ $\left( \pm 2.3 \times 10^{1}\right)$ copy number per $2.5 \times 10^{5}$ cells to $9.2 \times 10^{5}$ $\left( \pm 4.4 \times 10^{5}, \mathrm{p}<0.05\right)$ at MOI 0.25 and to $1.2 \times 10^{6}\left( \pm 3.9 \times 10^{5}\right.$, $\mathrm{p}<0.05)$ at MOI 1 ; MxA from $1.1 \times 10^{4}\left( \pm 1.4 \times 10^{3}\right)$ to $3.5 \times 10^{6}$ $\left( \pm 1.4 \times 10^{6}, \mathrm{p}<0.05\right)$ at MOI 0.25 and to $3.7 \times 10^{6}\left( \pm 1.3 \times 10^{6}\right.$, $\mathrm{p}<0.05)$ at MOI 1 ; OAS from $1.8 \times 10^{5}\left( \pm 4.4 \times 10^{4}\right)$ to $4.3 \times 10^{6}$ $\left( \pm 1.3 \times 10^{6}, \mathrm{p}<0.01\right)$ at MOI 0.25 and $4.0 \times 10^{6}\left( \pm 1.2 \times 10^{6}\right.$, $\mathrm{p}<0.01)$ at MOI 1 ; RIG-I from $2.0 \times 10^{5}\left( \pm 4.7 \times 10^{4}\right)$ to $1.5 \times 10^{6}$ $\left( \pm 4.7 \times 10^{5}, \mathrm{p}<0.05\right)$ at MOI 0.25 and $3.2 \times 10^{6}\left( \pm 1.1 \times 10^{6}\right.$, $\mathrm{p}<0.05)$ at MOI 1 ; and MDA5 from $3.2 \times 10^{4}\left( \pm 6.7 \times 10^{3}\right)$ to $2.5 \times 10^{5}\left( \pm 8.0 \times 10^{4}, \mathrm{p}<0.05\right)$ at MOI 0.25 and $2.8 \times 10^{5}$ $\left( \pm 6.8 \times 10^{4}, \mathrm{p}<0.01\right)$ at MOI 1 .

\section{AM increased RV1B-induced type I and type III IFN mRNA expression}

RV1B (MOI 1 and 0.25; fig. 1) induced type I and type III IFN and the effects of AM, EM and Tel pre-treatment on this were determined using real-time PCR. RV1B infection increased type I and type III IFN mRNA expression in HBECs $24 \mathrm{~h}$ postinfection. RV1B (MOI 1) induced IFN- $\beta$ (fig. 1a), IL-28 (fig. 1b) and IL-29 (fig. 1c) mRNA expression was nonsignificantly increased by $10 \mu \mathrm{M}$ and $50 \mu \mathrm{M}$ AM compared with RV1B infected cells. RV1B (MOI 0.25) induced IFN- $\beta$ (fig. 1d), IL-28 (fig. 1e) and IL-29 (fig. 1f) mRNA expression and this was nonsignificantly increased with $10 \mu \mathrm{M}$ AM and significantly increased with $50 \mu \mathrm{M}$ AM $(\mathrm{p}<0.05)$ compared with control (RV1B-infected cells). The effects of EM and Tel on RV-induced type I and type III IFN mRNA expression were also investigated but neither macrolide had any significant effect on RV1B-induced IFN or ISGs (data not shown).

\section{AM increased RV1B-induced ISG MRNA and protein expression}

RV1B (MOI 1 and 0.25; figs 2 and 3, respectively) induced ISG mRNA and the effects of AM, EM and Tel pre-treatment on this were determined using real-time PCR. RV1B (MOI 1) induced ISG mRNA expression was increased by AM at a concentration of $10 \mu \mathrm{M}$ and $50 \mu \mathrm{M}$ at 24 h post-infection and RIG-I (fig. 2a), OAS (fig. 2c), viperin (fig. 2d) and MxA (fig. 2e) mRNA expression were nonsignificantly increased by $10 \mu \mathrm{M}$ and significantly increased by $50 \mu \mathrm{M}$ AM $(\mathrm{p}<0.01, \mathrm{p}<0.001$, $p<0.01$ and $p<0.05$, respectively) compared with control (RV1B MOI 1). MDA5 mRNA expression was nonsignificantly increased by $10 \mu \mathrm{M}$ and $50 \mu \mathrm{M}$ AM compared with control (RV1B MOI 1; fig. 2b). To confirm the effects of AM on ISG mRNA, using western blotting, RV1B (MOI 1, fig. 4) induced ISG protein and the effects of AM on this were determined. RV1B-induced viperin, RIG-I, OAS and MxA protein were further increased by AM in a dose-dependent manner. AM did not induce any of these ISGs when administered alone (fig. 2f). The cytoskeletal protein $\alpha$-tubulin was used as load control. RV1B (MOI 0.25) induced ISG mRNA expression was increased by $\mathrm{AM}$ at a concentration of $10 \mu \mathrm{M}$ and $50 \mu \mathrm{M}$ at $24 \mathrm{~h}$ post-infection and RIG-I (fig. 3a), OAS (fig. 3c), viperin (fig. 3d) and MxA (fig. 3e) mRNA expression were nonsignificantly increased by $10 \mu \mathrm{M}$ and significantly increased by $50 \mu \mathrm{M}$ AM $(\mathrm{p}<0.01, \mathrm{p}<0.001$ and $\mathrm{p}<0.01$, respectively $)$ compared with control (RV1B MOI 0.25). MDA5 mRNA expression was nonsignificantly increased by $10 \mu \mathrm{M}$ AM and 

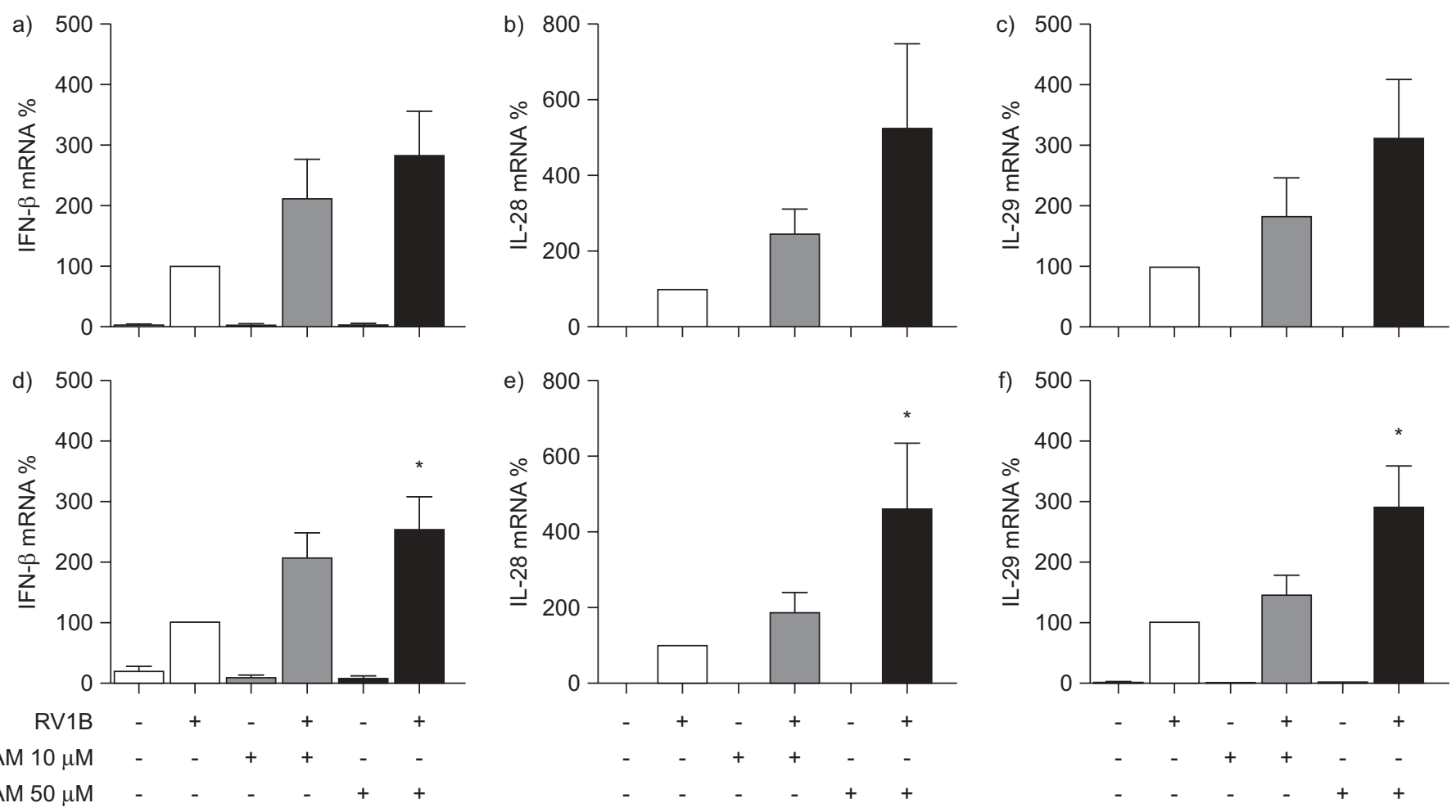

FIGURE 1. Azithromycin (AM) increased minor-group rhinovirus (RV) 1B-induced interferon (IFN) gene expression. Human bronchial epithelial cells were pre-treated with AM or medium for $24 \mathrm{~h}$ and infected with $\mathrm{a}, \mathrm{b}, \mathrm{c}$ ) RV1B at a multiplicity of infection (MOI) 1 or d, e, f) MOI 0.25, or treated with medium. AM- and RV1B-induced mRNA levels of a, d) IFN- $\beta, b, e)$ interleukin (IL)-28 and c, f) IL-29 were measured by real-time PCR at $24 \mathrm{~h}$ post-infection and data are presented as \% expression relative to infected control (i.e. RV1B-infected cells, $n=5$ ). *: $p<0.05$.

$50 \mu \mathrm{M}$ AM compared with control (RV1B; fig. 3b). The effects of EM and Tel on RV-induced ISG mRNA expression were also investigated but neither macrolide had any significant effect (data not shown).

\section{AM increased RV16-induced ISG mRNA and protein expression}

HBECs were also infected with major-group RV16 following pre-treatment with AM. Figure 4 shows that RV16-induced IFN- $\beta$ (fig. 4a), MxA (fig. 4b) and viperin (fig. 4c) was enhanced by $10 \mu \mathrm{M}$ AM and significantly augmented with $50 \mu \mathrm{M}$ AM $(\mathrm{p}<0.05, \mathrm{p}<0.05, \mathrm{p}<0.01$ versus RV16 control, respectively). To confirm the effects of AM on ISG induction, RV16-induced ISG protein and the effects of AM on this were determined by western blot. RV16-induced viperin and MxA protein were further increased by $\mathrm{AM}$ in a dose-dependent manner. AM did not induce any of these ISGs when administered alone. The cytoskeletal protein $\alpha$-tubulin was used as a load control. (fig. $4 \mathrm{~d}$ ).

\section{AM had no significant effects on RV1B-induced pro- inflammatory cytokines}

The effects of AM, EM and Tel on RV1B-induced IL-6 and IL-8 mRNA levels were determined by real-time PCR and RV1Binduced IL-8 and IL-6 protein levels were determined by ELISA (fig. 5). AM reduced IL-6 and IL-8 mRNA expression and protein levels modestly but not statistically significantly at either concentration at $24 \mathrm{~h}$ post-infection (fig. 5). The effects of EM and Tel on RV1B-induced IL- 8 and IL- 6 mRNA were also investigated but neither macrolide had any significant effect (data not shown).

\section{AM suppressed $R V$ replication and release}

The effects of AM, EM and Tel on RV1B and RV16 release and RNA was measured using a virus titration assay and quantitative PCR for viral RNA. RV1B RNA (fig. 6a) at $24 \mathrm{~h}$ and $48 \mathrm{~h}$ post-infection was nonsignificantly reduced by $10 \mu \mathrm{M}$ $\mathrm{AM}$ and significantly reduced by $50 \mu \mathrm{M}$ AM $(\mathrm{p}<0.001)$. At 48 h post-infection, $10 \mu \mathrm{M}$ AM also significantly reduced $\mathrm{RV} 1 \mathrm{~B}$ RNA abundance $(\mathrm{p}<0.001)$. Furthermore, the reduction by $50 \mu \mathrm{M}$ AM was significantly more than by $10 \mu \mathrm{M}$ AM $(p<0.001)$. RV1B release (fig. 6c) was significantly reduced by $50 \mu \mathrm{M} \mathrm{AM}$ at $24 \mathrm{~h}(\mathrm{p}<0.05)$ and $48 \mathrm{~h}(\mathrm{p}<0.001)$. AM at a concentration of $10 \mu \mathrm{M}$ had no significant effect on RV1B release. RV16 RNA abundance was significantly decreased by $50 \mu \mathrm{M}$ AM at $24 \mathrm{~h}(\mathrm{p}<0.01$; fig. $6 \mathrm{~b})$. RV16 RNA at $48 \mathrm{~h}$ was also decreased by AM, significantly by $50 \mu \mathrm{M}$ AM $(\mathrm{p}<0.001$; fig. $6 \mathrm{~b}$ ). RV16 release was not affected at $24 \mathrm{~h}$ post-infection; however, it was significantly affected using AM at $50 \mu \mathrm{M}$ $(p<0.05$; fig. $6 d)$. The effects of EM and Tel on RV1B release and replication were also investigated but neither macrolide had any significant effect on RV replication (data not shown).

\section{DISCUSSION}

The current treatment of asthma consists of corticosteroids and/or $\beta_{2}$-agonists and only partially prevents asthma exacerbations. A vital need exists for new treatment regimes for this form of asthma. Macrolide antibiotics have anti-inflammatory activity and possibly antiviral activity in airway epithelial cell 

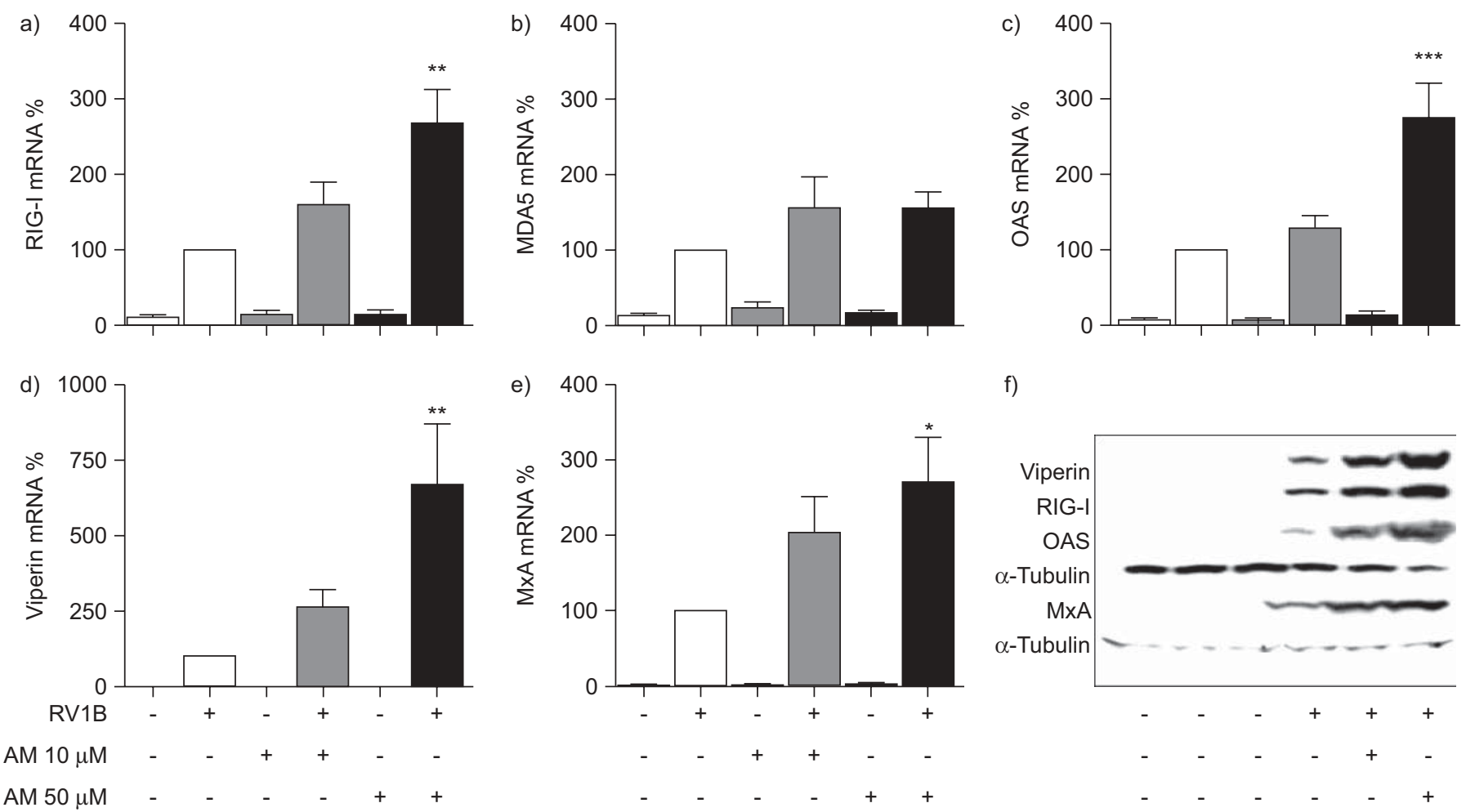

f)

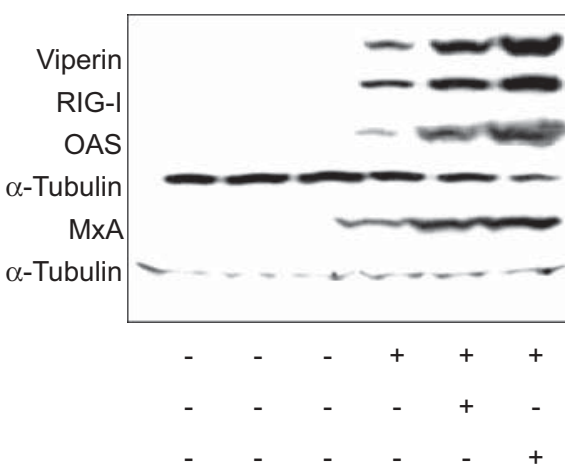

FIGURE 2. Azithromycin (AM) increased high-dose rhinovirus (RV) 1B-induced interferon-stimulated genes (ISGs). Human bronchial epithelial cells (HBECs) were pretreated with AM or medium for $24 \mathrm{~h}$ and infected with RV1B multiplicity of infection 1 or treated with medium. AM and RV1B-induced mRNA levels of a) retinoic acid inducible gene (RIG)-I, b) melanoma differentiation associated gene (MDA) 5, c) oligoadenylate synthetase (OAS), d) viperin and e) myxovirus resistance A (MxA), measured by realtime PCR at $24 \mathrm{~h}$ post-infection and data are presented as \% expression relative to control (RV1B-infected cells, $\mathrm{n}=5$ ). f) Both 10 and $50 \mu \mathrm{M}$ AM increased RV1B-induced ISG protein in HBECs compared with RV1B-infected cells (representative of three independent experiments). ${ }^{* *}: p<0.01 ; * * *: p<0.001$.
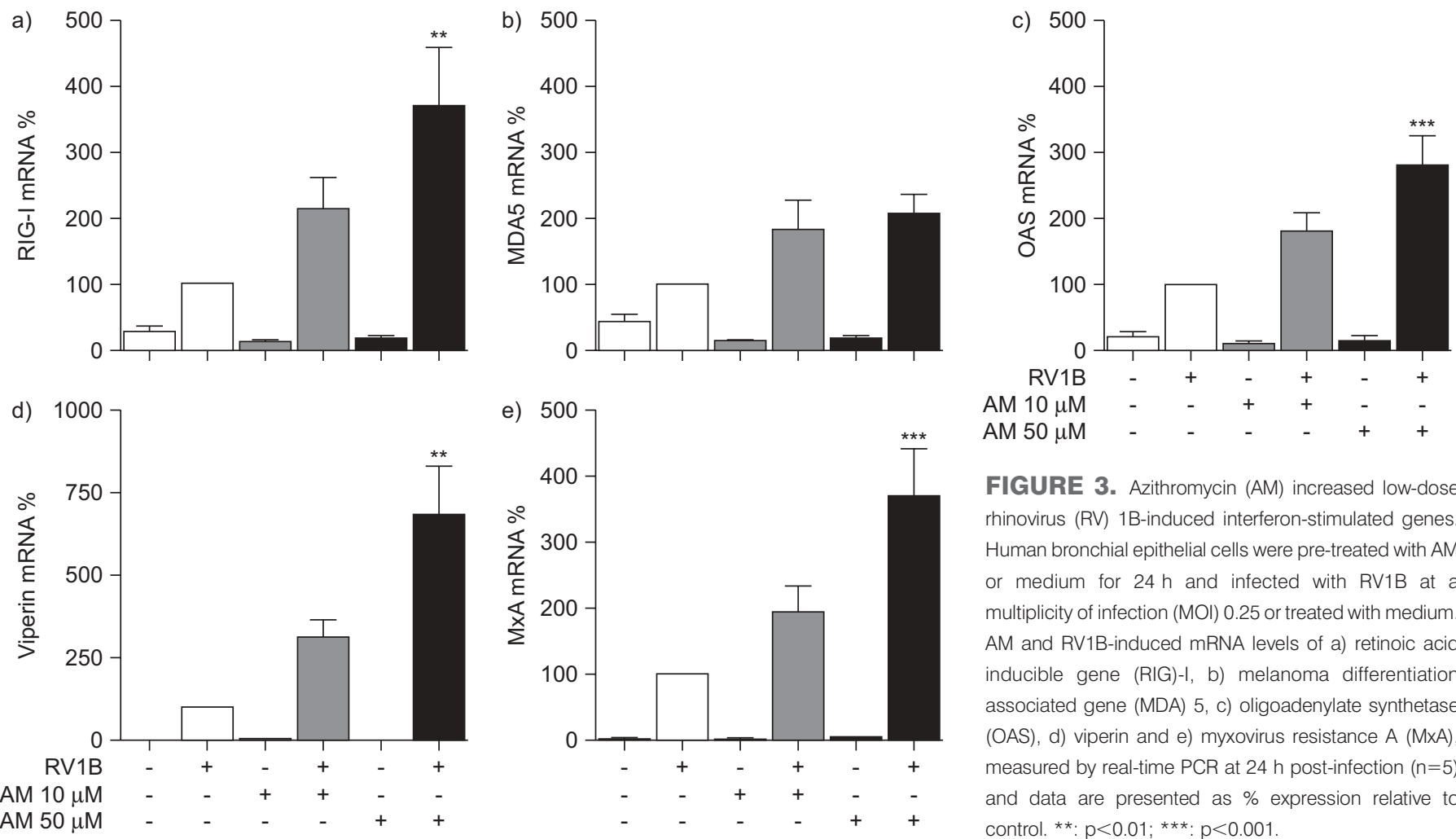

FIGURE 3. Azithromycin (AM) increased low-dose rhinovirus (RV) 1B-induced interferon-stimulated genes. Human bronchial epithelial cells were pre-treated with AM or medium for $24 \mathrm{~h}$ and infected with RV1B at a multiplicity of infection (MOI) 0.25 or treated with medium. AM and RV1B-induced mRNA levels of a) retinoic acid inducible gene (RIG)-I, b) melanoma differentiation associated gene (MDA) 5, c) oligoadenylate synthetase $(\mathrm{OAS})$, d) viperin and e) myxovirus resistance $\mathrm{A}(\mathrm{M} \times \mathrm{A})$, measured by real-time PCR at $24 \mathrm{~h}$ post-infection $(n=5)$ and data are presented as \% expression relative to control. ${ }^{*}$ : $p<0.01 ; * * *: p<0.001$ 

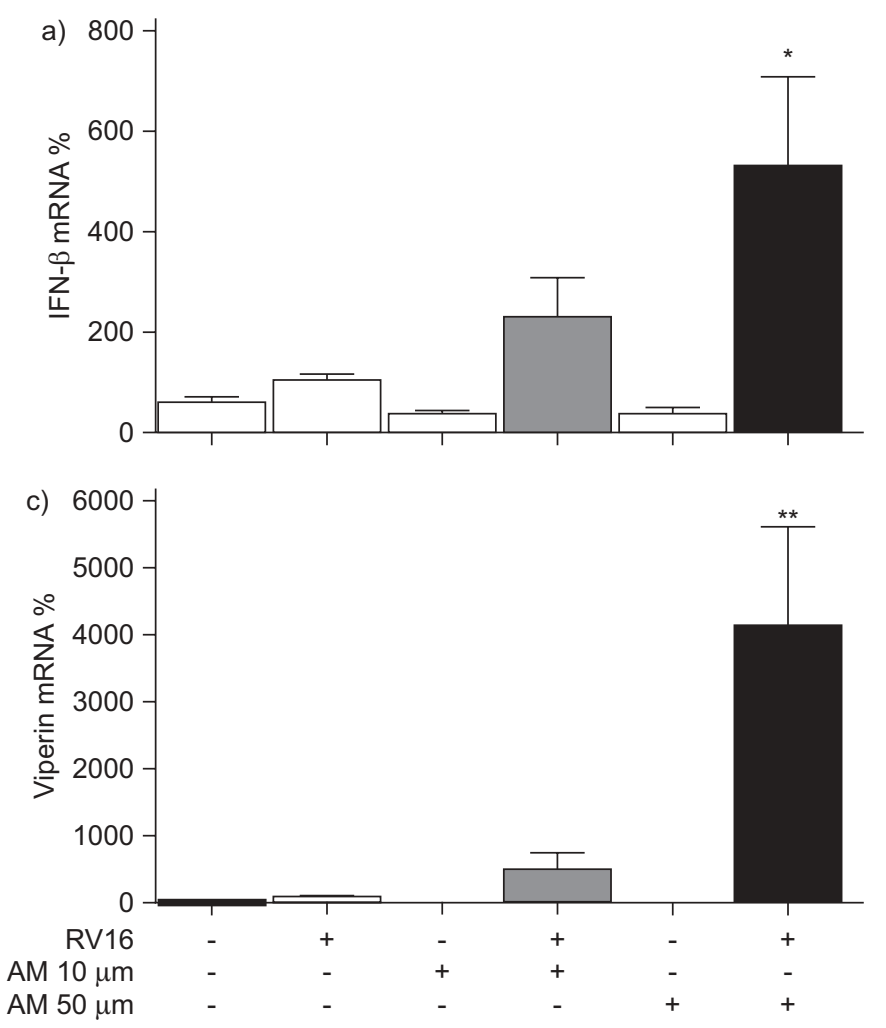

b)

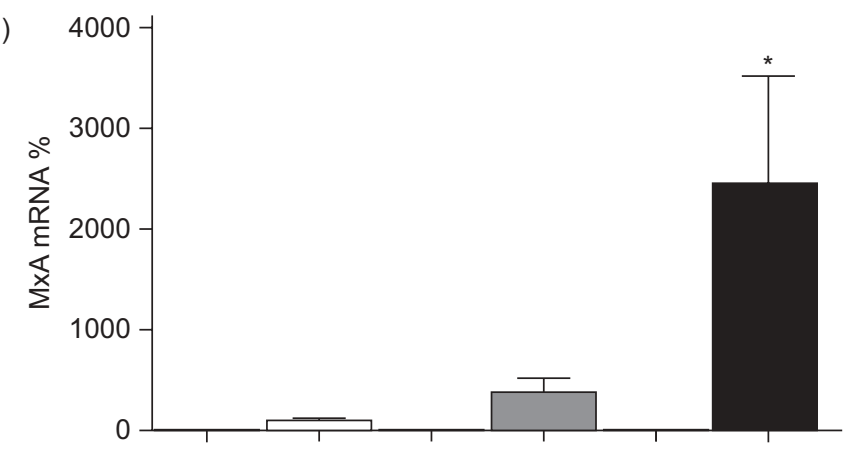

d)

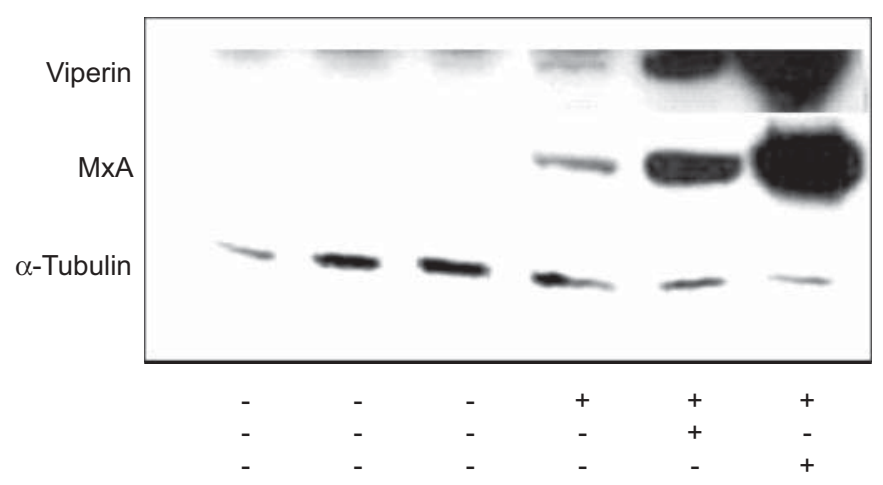

FIGURE 4. Azithromycin (AM) increased major-group rhinovirus (RV)-induced interferon (IFN)-stimulated genes (ISGs). Human bronchial epithelial cells (HBECs) were pretreated with AM or medium for $24 \mathrm{~h}$ and infected with RV16 at a multiplicity of infection 1 or treated with medium. AM and RV1B-induced mRNA levels of a) IFN- $\beta$, b) myxovirus resistance $A(M \times A)$ and c) viperin were measured by real-time PCR at $24 \mathrm{~h}$ post-infection $(n=5)$ and data are presented as \% expression relative to RV16-infected cells. d) Both 10 and $50 \mu \mathrm{M}$ AM increased RV16-induced ISG protein in HBECs compared with RV16 infected cells (figure is representative of three experiments). *: $p<0.05$; **: $p<0.01$.

lines [24, 26, 27], although the exact a mechanism of this is unclear. In our study, AM, but not EM or Tel, increased RVinduced IFN and ISG responses and reduced RV replication and release in HBECs. The macrolides had no anti-inflammatory effect.

Several macrolide antibiotics have anti-inflammatory effects, demonstrated by inhibition of the production of pro-inflammatory cytokines in vitro [22, 24-28, 32]. This effect occurs via suppression of NF- $\mathrm{B}$ activation in HBECs [22, 24, 32]. Reduction of cytokines, such as IL- 6 and IL- 8 can be an advantageous mechanism that leads to attenuation of airway inflammation. Other studies have reported anti-inflammatory activity of clarithromycin, bafilomycin A1 and EM on majorgroup RV infection, and minor-group RV infection for EM, in airway epithelial cells showing reduction of RV induced proinflammatory cytokines [24, 26, 27]. In the present study, we showed no significant reduction of RV1B-induced IL-6 and IL-8 mRNA and protein by AM, EM or Tel. These data question the anti-inflammatory potential of macrolides and the mechanism of this in bronchial epithelial cells.

The conflicting results observed in studies with various macrolides may be explained by differences in the experimental model. In the present study, using primary bronchial epithelial cells, we used shorter incubation times with the macrolides and sampled at $24-48 \mathrm{~h}$ post-RV infection, as primary bronchial epithelial cells are more susceptible to RV infection than cell lines, requiring a shorter duration of experimentation. The reduction of RV-induced anti-inflammatory cytokines previously observed by macrolides is also modest, at best. The reduction of pro-inflammatory molecules by macrolides in micromolar concentrations range from 80 to $25 \%$ [24, 26, 27]. In contrast, corticosteroids reduce RV-induced pro-inflammatory cytokine production by $70-85 \%$ in bronchial epithelial cells using nanomolar concentrations [33]. Therefore, the anti-inflammatory effects observed with macrolides are modest if compared to the anti-inflammatory effects of corticosteroids and require much higher doses, questioning their real use as anti-inflammatory agents.

A possible mechanism of anti-RV activity of macrolides has been demonstrated as reduction of ICAM-1, the receptor of major group RVs. However, the anti-RV effects of macrolides cannot be completely explained by this. A range of studies have suggested that macrolides inhibit replication of both major and minor groups of RV [24, 26, 27]. Furthermore, a study by SUZUKI et al. [27] observed anti-viral effects of EM on minor group RV2, but no reduction in the low-density lipoprotein receptor, the receptor for minor group RV. Our study further supports that the anti-viral effects of macrolides are not completely dependent on reduction of ICAM-1, as our results show suppression of viral replication with minor-group $\mathrm{RV} 1 \mathrm{~B}$ and major-group RV16, which therefore cannot be explained by reduction of the major group RV receptor, ICAM-1.

In our studies, AM reduced RV1B and RV16 replication and release into supernatants, and increased ISG gene and protein 

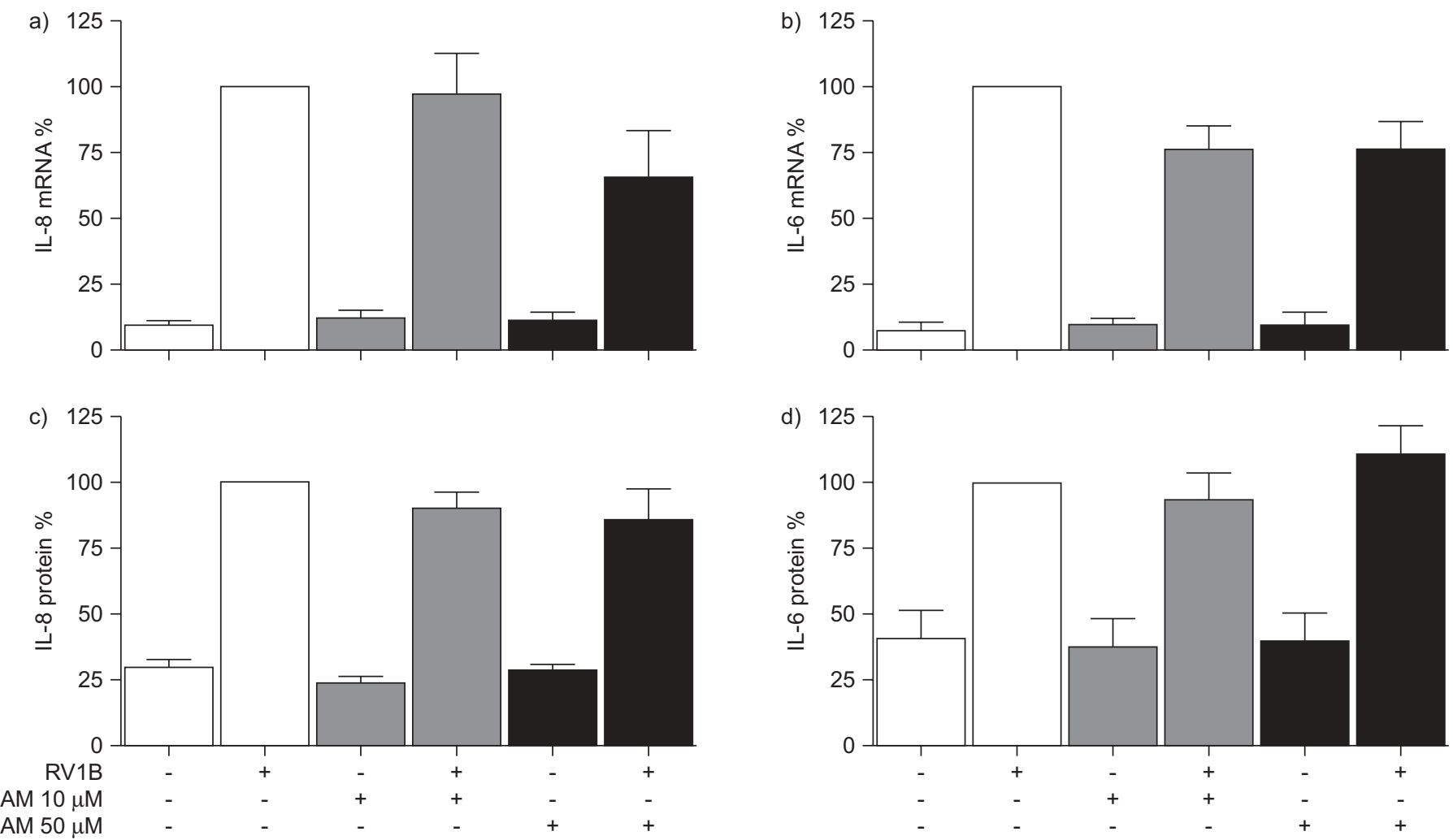

FIGURE 5. Azithromycin (AM) had no effect on rhinovirus (RV)-induced pro-inflammatory cytokines. Human bronchial epithelial cells (HBECs) were pre-treated with AM or medium for $24 \mathrm{~h}$ and infected with RV1B at a multiplicity of infection 1 or treated with medium. AM and RV1B at a concentration of either 10 or $50 \mu \mathrm{M}$ did not significantly increase RV1B-induced a) interleukin (IL)-8 mRNA, b) IL-6 mRNA, as measured by real-time PCR at $24 \mathrm{~h}$ post-infection, or c) IL-8 protein or d) IL-6 protein as measured by ELISA at $24 \mathrm{~h}$ post-infection compared with control (RV1B infected cells, $\mathrm{n}=5$ ).

expression. The ISGs studied have been shown to have antiviral activity. Recently viperin, one of the RV-induced ISGs increased by AM, is required for the host defence against RV infection in HBECs [34]. The antiviral role for the other ISGs investigated in the present study have not been yet established to have rhinoviral activity in bronchial epithelial cells, yet are well established in other viral infections [35, 36].

AM also induced the mRNA and protein of the important intracellular dsRNA and ssRNA pattern recognition molecules, RIG-I and MDA5, required for IFN- $\beta$ induction [18]. Hence, not only are macrolides responsible for direct induction of antiviral genes, but they also upregulate the sensors of viral infection. This may be desirable for use as a therapeutic treatment given shortly after viral infection, whereby macrolides, if given topically to the airway during viral infection, could potentially increase the number of sensory molecules ready to detect and respond to replicating viral nucleic acid.

We found that the macrolides did not induce antiviral genes by themselves. Currently we do not understand the mechanism of how AM induces anti-viral activity in the presence of RV infection. Antiviral ISGs can be induced via IRF transcription factors following virus infection [37]. One possible mechanism of AM could be activation of signalling pathways including IкBkinase (IKK)- $\beta$ [38], IKK-1/ $\varepsilon$ [37] and TBK-1 [39], producing interferon-regulatory factor (IRF) activation. Alternatively, macrolides may act via the type I IFN receptor complex
(IFNAR1), inducing IRF9, IRF7 and STAT1/2, producing the transcription factor ISGF3 $[40,41]$. AM could, in theory, act on the IFNAR1 complex, or the receptor complex for IL-29 and IL-28 [42].

In vivo studies of macrolides have shown contradictory results. Clarythromycin had no effect on the development of cold symptoms and nasal inflammation In contrast, the TELICAST (telithromycin in acute exacerbations of asthma) study demonstrated the potential benefits of the macrolide antibiotic Tel in the treatment of asthma exacerbations [29]. Whether the success of the TELICAST study was in part due to antiviral activity is unknown. Interestingly, we found no antiviral activity of Tel in vitro, suggesting that the positive effect of Tel in asthma exacerbations is either unrelated to virus infection or through antiviral properties in other cell types and different immune responses during infection. These data demonstrate that, although studies in cell lines are important and useful in defining mechanisms, results need to be confirmed in vivo. A similar study examining the effects of AM as a treatment for asthma exacerbations would therefore be appealing.

In summary, we present a possible new mechanism of antirhinoviral activity of macrolides in HBECs. This is the first study showing antiviral effects of macrolides in primary HBECs, which is the site of infection of RV in vivo and therefore important in rhinovirus induced asthma exacerbations $[43,44]$. While only modest, the upregulation of IFNs and 

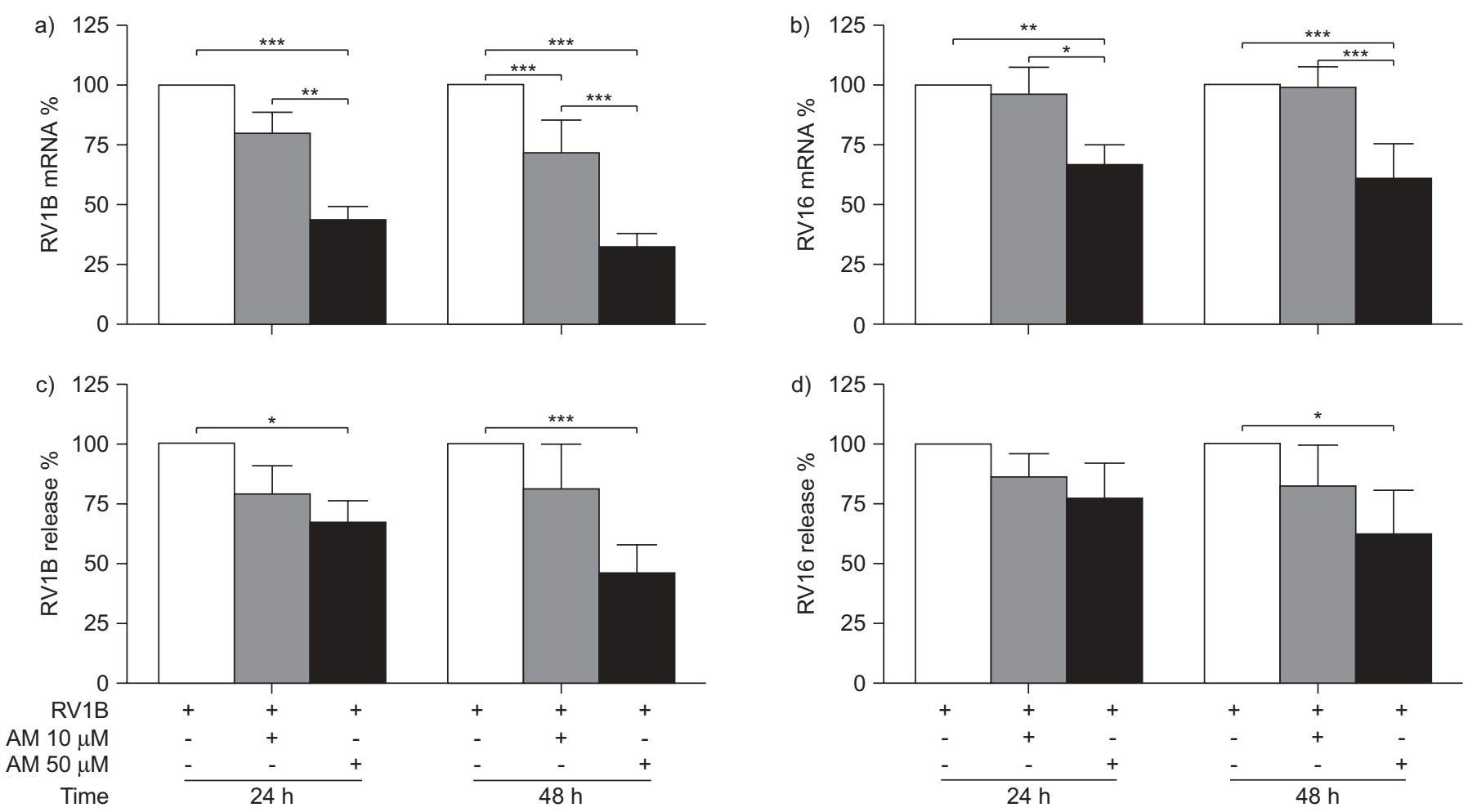

FIGURE 6. Azithromycin (AM) reduced rhinovirus (RV) 1B and RV16 replication. Human bronchial epithelial cells were pre-treated with $\mathrm{AM}$ or medium for $24 \mathrm{~h}$ and infected with RV1B or RV16 at a multiplicity of infection 1. a) At a concentration of $50 \mu \mathrm{M}$, AM decreased RV1B RNA at $24 \mathrm{~h}$, and also with 10 and $50 \mu \mathrm{M}$ at $48 \mathrm{~h}$ post-infection, as assessed by real-time PCR. b) At a concentration of $50 \mu \mathrm{M}$, AM decreased RV16 RNA at $24 \mathrm{~h}$, and also with $50 \mu \mathrm{M}$ at $48 \mathrm{~h}$ post-infection, as assessed by real-time PCR. C) AM at a concentration of $50 \mu \mathrm{M}$ reduced RV1B release at $24 \mathrm{~h}$ and $48 \mathrm{~h}(\mathrm{n}=8)$. d) AM at a concentration of $50 \mu \mathrm{M}$ reduced RV16 release at $48 \mathrm{~h}(\mathrm{n}=5)$. Data are presented as $\%$ relative to control. *: $p<0.05 ;{ }^{* *}: p<0.01 ;{ }^{* *}: p<0.001$

ISGs and suppression of RV replication may have consequences on asthma exacerbations and may further explain the antiviral effects seen in previous studies. The importance and protective role of IFN- $\beta$ and IFN- $\lambda$ in asthma exacerbations have recently been shown $[12,13]$, and epidemiological studies have provided a model of the disease burden associated with RV-induced asthma exacerbations. Whether the antiviral effects of AM can be used as a therapeutic treatment for asthma exacerbations requires further study in appropriate animal and human models.

\section{STATEMENT OF INTEREST}

A statement of interest for the present study can be found at www.erj. ersjournals.com/misc/statements.dtl

\section{ACKNOWLEDGEMENTS}

We thank Sanofi-Aventis (Guildford, UK) for supplying telithromycin.

\section{REFERENCES}

1 Corne JM, Marshall C, Smith S, et al. Frequency, severity, and duration of rhinovirus infections in asthmatic and non-asthmatic individuals: a longitudinal cohort study. Lancet 2002; 359: 831-834.

2 Grissell TV, Powell H, Shafren DR, et al. Interleukin-10 gene expression in acute virus-induced asthma. Am J Respir Crit Care Med 2005; 172: 433-439.

3 Chauhan AJ, Inskip HM, Linaker $\mathrm{CH}$, et al. Personal exposure to nitrogen dioxide $\left(\mathrm{NO}_{2}\right)$ and the severity of virus-induced asthma in children. Lancet 2003; 361: 1939-1944.
4 Johnston SL, Pattemore PK, Sanderson G, et al. Community study of role of viral infections in exacerbations of asthma in 9-11 year old children. BMJ 1995; 310: 1225-1229.

5 Johnston NW, Sears MR. Asthma exacerbations. 1: epidemiology. Thorax 2006; 61: 722-728.

6 Wark PA, Gibson PG. Asthma exacerbations. 3: Pathogenesis. Thorax 2006; 61: 909-915.

7 FitzGerald JM, Becker A, Sears MR, et al. Doubling the dose of budesonide versus maintenance treatment in asthma exacerbations. Thorax 2004; 59: 550-556.

8 Johnston NW, Johnston SL, Duncan JM, et al. The September epidemic of asthma exacerbations in children: a search for etiology. J Allergy Clin Immunol 2005; 115: 132-138.

9 Murray CS, Poletti G, Kebadze T, et al. Study of modifiable risk factors for asthma exacerbations: virus infection and allergen exposure increase the risk of asthma hospital admissions in children. Thorax 2006; 61: 376-382.

10 O'Byrne PM, Bisgaard H, Godard PP, et al. Budesonide/ formoterol combination therapy as both maintenance and reliever medication in asthma. Am J Respir Crit Care Med 2005; 171: 129-136.

11 Pauwels RA, Lofdahl CG, Postma DS, et al. Effect of inhaled formoterol and budesonide on exacerbations of asthma. Formoterol and Corticosteroids Establishing Therapy (FACET) International Study Group. N Engl J Med 1997; 337: 1405-1411.

12 Contoli M, Message SD, Laza-Stanca V, et al. Role of deficient type III interferon- $\lambda$ production in asthma exacerbations. Nat Med 2006; 12: 1023-1026.

13 Wark PA, Johnston SL, Bucchieri F, et al. Asthmatic bronchial epithelial cells have a deficient innate immune response to infection with rhinovirus. J Exp Med 2005; 201: 937-947. 
14 Khaitov MR, Laza-Stanca V, Edwards MR, et al. Respiratory virus induction of $\alpha-, \beta$ - and $\lambda$-interferons in bronchial epithelial cells and peripheral blood mononuclear cells. Allergy 2009; 64: 375-386.

15 Staeheli P, Haller O. Interferon-induced human protein with homology to protein $\mathrm{Mx}$ of influenza virus-resistant mice. Mol Cell Biol 1985; 5: 2150-2153.

16 Chin KC, Cresswell P. Viperin (cig5), an IFN-inducible antiviral protein directly induced by human cytomegalovirus. Proc Natl Acad Sci USA 2001; 98: 15125-15130.

17 Hovanessian AG. Interferon-induced and double-stranded RNAactivated enzymes: a specific protein kinase and 2', 5'-oligoadenylate synthetases. J Interferon Res 1991; 11: 199-205.

18 Yoneyama M, Kikuchi M, Natsukawa T, et al. The RNA helicase RIG-I has an essential function in double-stranded RNA-induced innate antiviral responses. Nat Immunol 2004; 5: 730-737.

19 Kang DC, Gopalkrishnan RV, Wu Q, et al. MDA-5: an interferoninducible putative RNA helicase with double-stranded RNAdependent ATPase activity and melanoma growth-suppressive properties. Proc Natl Acad Sci USA 2002; 99: 637-642.

20 Chinali G, Nyssen E, Di GM, et al. Inhibition of polypeptide synthesis in cell-free systems by virginiamycin $S$ and erythromycin. Evidence for a common mode of action of type B synergimycins and 14-membered macrolides. Biochim Biophys Acta 1988; 949: 71-78.

21 Takizawa H, Desaki M, Ohtoshi T, et al. Erythromycin suppresses interleukin 6 expression by human bronchial epithelial cells: a potential mechanism of its anti-inflammatory action. Biochem Biophys Res Commun 1995; 210: 781-786.

22 Takizawa H, Desaki M, Ohtoshi T, et al. Erythromycin modulates IL-8 expression in normal and inflamed human bronchial epithelial cells. Am J Respir Crit Care Med 1997; 156: 266-271.

23 Tamaoki J, Sakai N, Tagaya E, et al. Macrolide antibiotics protect against endotoxin-induced vascular leakage and neutrophil accumulation in rat trachea. Antimicrob Agents Chemother 1994; 38: 1641-1643.

24 Jang YJ, Kwon HJ, Lee BJ. Effect of clarithromycin on rhinovirus16 infection in A549 cells. Eur Respir J 2006; 27: 12-19.

25 Khair OA, Devalia JL, Abdelaziz MM, et al. Effect of erythromycin on Haemophilus influenzae endotoxin-induced release of IL-6, IL-8 and sICAM-1 by cultured human bronchial epithelial cells. Eur Respir J 1995; 8: 1451-1457.

26 Suzuki T, Yamaya M, Sekizawa $K$, et al. Bafilomycin $A_{1}$ inhibits rhinovirus infection in human airway epithelium: effects on endosome and ICAM-1. Am J Physiol Lung Cell Mol Physiol 2001; 280: L1115-L1127.

27 Suzuki T, Yamaya M, Sekizawa K, et al. Erythromycin inhibits rhinovirus infection in cultured human tracheal epithelial cells. Am J Respir Crit Care Med 2002; 165: 1113-1118.

28 Desaki M, Takizawa H, Ohtoshi T, et al. Erythromycin suppresses nuclear factor- $\mathrm{\kappa B}$ and activator protein-1 activation in human bronchial epithelial cells. Biochem Biophys Res Commun 2000; 267: 124-128.
29 Johnston SL, Blasi F, Black PN, et al. The effect of telithromycin in acute exacerbations of asthma. $N$ Engl J Med 2006; 354: 1589-1600.

30 Papi A, Johnston SL. Rhinovirus infection induces expression of its own receptor intercellular adhesion molecule 1 (ICAM-1) via increased NF-кB-mediated transcription. J Biol Chem 1999; 274 9707-9720.

31 Johnston SL, Tyrrell DA. Rhinoviruses In: Lennette ED, Schmidt NJ, eds. Diagnostic Procedures for Viral, Rickettsial and Chlamydial Infections. Washington, DC, American Public Health Association, 2005; pp. 253-263.

32 Takizawa H, Desaki M, Ohtoshi T, et al. Erythromycin suppresses interleukin 6 expression by human bronchial epithelial cells: a potential mechanism of its anti-inflammatory action. Biochem Biophys Res Commun 1995; 210: 781-786.

33 Edwards MR, Haas J, Panettieri RA Jr, et al. Corticosteroids and $\beta_{2}$ agonists differentially regulate rhinovirus-induced interleukin-6 via distinct cis-acting elements. J Biol Chem 2007; 282: 15366-15375.

34 Proud D, Turner RB, Winther B, et al. Gene expression profiles during in vivo human rhinovirus infection: insights into the host response. Am J Respir Crit Care Med 2008; 178: 926-968.

35 Haller O, Kochs G, Weber F. Interferon, Mx, and viral countermeasures. Cytokine Growth Factor Rev 2007; 18: 425-433.

36 Castelli J, Wood KA, Youle RJ. The 2-5A system in viral infection and apoptosis. Biomed Pharmacother 1998; 52: 386-390.

37 Mori M, Yoneyama M, Ito T, et al. Identification of Ser-386 of interferon regulatory factor 3 as critical target for inducible phosphorylation that determines activation. J Biol Chem 2004; 279: 9698-9702.

38 Chu WM, Ostertag D, Li ZW, et al. JNK2 and IKK $\beta$ are required for activating the innate response to viral infection. Immunity 1999; 11: 721-731.

39 McWhirter SM, Fitzgerald KA, Rosains J, et al. IFN-regulatory factor 3-dependent gene expression is defective in Tbk1-deficient mouse embryonic fibroblasts. Proc Natl Acad Sci USA 2004; 101: 233-238.

40 Ghislain JJ, Wong T, Nguyen M, et al. The interferon-inducible Stat2:Stat1 heterodimer preferentially binds in vitro to a consensus element found in the promoters of a subset of interferonstimulated genes. J Interferon Cytokine Res 2001; 21: 379-388.

41 Harada $H$, Matsumoto $M$, Sato $M$, et al. Regulation of IFN- $\alpha / \beta$ genes: evidence for a dual function of the transcription factor complex ISGF3 in the production and action of IFN- $\alpha / \beta$. Genes Cells 1996; 1: 995-1005.

42 Kotenko SV, Gallagher G, Baurin VV, et al. IFN- $\lambda$ s mediate antiviral protection through a distinct class II cytokine receptor complex. Nat Immunol 2003; 4: 69-77.

43 Fleming HE, Little FF, Schnurr D, et al. Rhinovirus-16 colds in healthy and in asthmatic subjects: similar changes in upper and lower airways. Am J Respir Crit Care Med 1999; 160: 100-108.

44 Papadopoulos NG, Bates PJ, Bardin PG, et al. Rhinoviruses infect the lower airways. J Infect Dis 2000; 181: 1875-1884. 